\title{
Encoding variability theory and the spacing effect in associate learning
}

\author{
JAMES F. BRAY, DONALD ROBBINS, and WILLIAM B. WITCHER, JR. \\ Emory University, Atlanta, Georgia 30922
}

\begin{abstract}
Encoding variability theory accounts for the spacing effect by assuming that, as the lag between repetitions increases, the memorial representations approach independence. A method for testing this assumption in determining repetition effects in associative learning is suggested. In the independence hypothesis, we simply assume that each presentation of a word pair is represented independently, so that the expected proportion recalled is simple, $P=P_{1}+P_{2}-P_{1} P_{2}$. Two studies are reported using a continuous paired-associate task representing a factorial combination of lag and retention interval as well as single-presentation control conditions. The results indicate that for moderately long retention intervals, as the lag between repetitions increases, the observed proportion recalled is first less, then eventually exceeds, and then returns to the level expected by an independence hypothesis.
\end{abstract}

A question of central importance in learning theory is how effective is a repetition? This immediately leads to the study of trial distribution effects. Attempts to answer this question in associative learning have concentrated on studies manipulating the lag or spacing between repetitions. In particular, using a continuous paired-associate study-test paradigm or a Peterson and Peterson (1959) task, a number of interesting phe. nomena have been uncovered. When a long retention interval is used, increasing the lag between repetitions leads to an increase in recall, hence the lag or spacing effect (see Bjork, 1970; Melton, 1970). However, a limit has been found for the spacing effect, so that for very long lags the proportion of recall begins to decline. As a result, the function relating recall proportion and lag for long retention intervals is concave downward (Bellezza, Winkler, \& Andrasik, 1975; Peterson, Wampler, Kirkpatrick, \& Saltzman, 1963; Robbins \& Bray, 1974b; Young, 1971). Further, Peterson, Hillner, and Saltzman (1962) found that, when the retention interval was short, the proportion recalled decreased as the lag between repetitions increased. This interaction between lag and retention interval has recently been replicated using a continuous paired-associate task (Robbins \& Bray, 1974a, b).

A variety of theories have been proposed to account for the lag effect (e.g., Bjork, 1970; Hintzman, 1974; Robbins, 1973). All of these theories make various assumptions about how an event is represented in memory, what occurs during the lag interval, and the

This research was supported by a grant from the Emory University Gradiate School of Arts and Sciences. Experiment I is based on a thesis submitted in partial fulfillment of the requirements for the MA degree at Emory University, August 1973 , by JFB, and Experiment II was submitted in partial fulfillment of the requirements for an Honors Thesis in psychology by WBW, Jr. Reprint requests should be sent to Donald Robbins, Department of Psychology, Emory University, Atlanta, Georgia 30322 . effect of a repetition on the memorial representation.

Most of these theories assume that either a repetition effects the processing of the first presentation or that the first presentation effects the processing of the repetition. Whether the process is one of consolidation (Peterson, 1966), rehearsal (Atkinson \& Shiffrin, 1968), attention (Greeno, 1970), or habituation (Hintzman, 1974), they all imply a relationship between the lag between repetitions and the effect on processing the information, and, therefore, recall level (see Hintzman, 1974, for a review of these theories). However, another class of theories that emphasizes encoding variability have a very different implication with regard to repetition effects. For example, Melton (1970) argues that the longer the lag, the more likely it is that the memorial representations are independent, thus yielding more possible retrieval routes in contrast to a massed repetition. This implies that an item with two encodings is more likely to be recalled than an item with just one encoding. Bellezza et al. (1975) recently reported data that led them to the opposite conclusion, i.e., that a repetition is more effective if one code is formed and elaborated than if a different code is formed with each repetition. However, they did not explicitly test the assumption of encoding variability theory that increasing the lag leads to independent representations, i.e., multiple codings.

An explicit test would seem to be to establish expected recall levels, assuming that the two events (i.e., the initial presentation and its subsequent repetition) are represented independently in memory. A comparison of observed recall data with that expected by an independence assumption should yield a high degree of correspondence if the encoding variability notion is correct.

The independence hypothesis has been used in evaluating repetition effects in a free recall task. Glanzer (1969), Glanzer and Duarte (1971), and Paivio (1974) 
have all found that, as the lag increased, the proportion recalled approached that expected by an independence assumption. Madigan (1969) and Melton (1970) have reported that, at lags greater than five in a free recall task, the observed proportion recalled was greater than that expected by an independence assumption.

We propose to use this method to test the independence assumption of encoding variability theory in evaluating repetition effects in a paired-associate task. Let us denote the initial presentation of a pair as $P_{1}$, and the repetition as $P_{2}$. The lag between $P_{1}$ and $P_{2}$ is, in general, $\mathrm{n}$ trials, consisting of presentations or tests of other pairs. The retention interval, the $P_{2}$ to test interval is, in general, $r$ trials long. What is needed to evaluate repetition effects are single-presentation items that are tested $n+r+1$ trials later, which represents the expected proportion recalled for $P_{1}$. Similarly, single-presentation items tested $r$ trials later would represent the expected proportion recalled for $P_{2}$. The independence hypothesis is then easily arrived at, i.e., $P=P_{1}+P_{2}-P_{1} P_{2}$.

Despite the number of paired-associate spacing studies, few, if any, contain the appropriate control items for a proper evaluation of the independence hypothesis. As a result, in Experiment I, a 6 by 3 factorial combination of lag and retention interval was used in a continuous paired-associate task. In addition, 14 single-presentation conditions were included to evaluate the independence hypothesis. In the first study, both presentations and tests were at a 5 -sec rate and were thus experimenter controlled. In Experiment II, the tests were subject paced to evaluate the possibility that the concave downward function of recall level and lag for long retention intervals was due to a retrieval time problem.

\section{EXPERIMENT I}

\section{Method}

Design. Each subject received four pairs of common English words in each of 32 conditions. There were 14 single-presentation conditions, followed by $0,1,3,4,5,7,8,9,11,12,13$, 15,17 , or 19 pairs or tests of other pairs, i.e., trials, and then a test trial. Since the presentation rate was $5 \mathrm{sec}$, the retention interval for these conditions ranged from 0 to $95 \mathrm{sec}$. The remaining 18 conditions represented a factorial combination of one, two, three, five, seven, or nine trials $(5,10,15,25,35$, or $45 \mathrm{sec})$ presented in the interval between repetitions and one, five, or nine trials $(5,25$, or $45 \mathrm{sec})$ in the retention interval.

One of each of the 32 conditions was represented in a list and four such lists were presented to each subject. Filler items were inserted wherever necessary to obtain the appropriate spacing conditions. All of the filler items were tested, but the data from these items were not included in the analyses. Each group of subjects (group size ranged from one to five persons) received a different random order of the four lists. Word pairs were reassigned to conditions for approximately every other group. The lists were administered essentially continuously (a few seconds were involved in changing slide trays on the projector at the end of each list), so that a continuous pairedassociate procedure resulted.
Subjects. Fifty subjects were recruited from summer school classes at Emory University. The subjects took part in a single session which lasted approximately $1 \mathrm{~h}$ for which they were paid $\$ 2$.

Materials. The stimuli were pairs of six-letter English words with a Thorndike-Lorge (1944) frequency count of 10 or more. The words were randomly assigned to pairs, with the restriction that obviously associated words were not paired and that both words of a pair did not begin with the same letter.

Procedure. The subjects were tested in small groups. They were given instructions which informed them of the nature of the study (presentation of pairs) and test trials (stimulus words only) and were also told that some pairs would be presented once and some twice. They were told that the object was to be correct as of ten as possible on the test trials. No feedback was given on test trials.

The study and test trials were presented visually at a 5 -sec rate with a projector. The study trials had the two words centered on the slide, with the stimulus word above the response word. Test trials showed the stimulus word in the center of the slide, and subjects had $5 \sec$ to write down the appropriate response on sheets provided for this purpose. The response sheets contained the numbers $1-200$ and subjects were told (and monitored) to place a dash whenever they could not think of a response word. The subjects were given a practice series to familiarize them with the study-test procedure.

\section{EXPERIMENT II}

\section{Method}

Design. This study replicated one of the repetition conditions of Experiment I. Each subject received six repetition conditions and 10 single-presentation conditions. The repetitions had lags of one, two, three, five, seven, or nine trials between them, and all had a retention interval of five intervening trials. The singlepresentation conditions were tested after $0,1,3,5,7,8,9,11$, 13 , or 15 trials. The major difference between this study and Experiment 1 was that, although study trials were presented at a $5-\mathrm{sec}$ rate, the test trials were subject paced. As a result, the subjects were given as much time as they desired to respond (either with a response or "I don't know it") and the response time was recorded.

One of each of the 16 conditions was represented in a list and nine such lists were presented to each subject. Filler items were inserted wherever necessary to obtain the appropriate spacing conditions. All of the filler items were tested, but the data from these items were not included in the analysis. Each subject received a different random order of the nine lists, which were administered continuously with the exception of slide tray change time. Word pairs were reassigned to conditions for approximately every five subjects.

Subjects. Twenty-five subjects from the Emory University introductory psychology subject pool took part in a single session which lasted approximately $1 \mathrm{~h}$.

Materials and procedure. The subjects were tested individually. The materials and general procedure were the same as in Experiment I. The study trials were presented visually for $5 \mathrm{sec}$ with a projector on a $7.62 \times 12.70 \mathrm{~cm}$ rear-view projection screen. On test trials, a millisecond clock was activated when the shutter was released and the stimulus word was displayed on the screen. The subjects were told to say the response aloud and depress the screen which stopped the clock. They were also told that if they did not know the response word, they were to say "I don't know," and also depress the screen. The subjects were given a practice series to familiarize them with the procedure. In addition, the first of the nine lists was also used as further practice. As a result, the data reported are based on the last eight lists. 


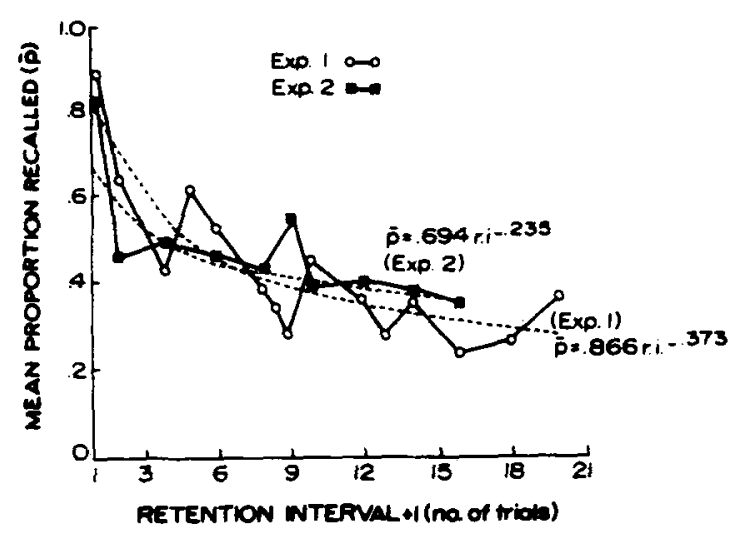

Figure 1. Mean proportion recalled as a function of retention interval. The dashed lines represent the best-fitting power functions and the solid lines the obtained values.

\section{RESULTS}

Figure 1 shows that the proportion recalled decreased as the retention interval increased for the singlepresentation conditions in both Experiments I and II, although the function is not as smooth as one might have expected (e.g., Peterson \& Peterson, 1959; Young, 1971).

Figure 2 reveals that for the repetition conditions in Experiment $I$, when the retention interval contained one trial, the proportion recalled as a function of Lag was relatively flat. However, when the retention interval was five or nine trials, the function was concave downward. These observations were confirmed by an analysis of variance that revealed significant effects of Lag $\left[\mathrm{F}(5,120)=9.31, \mathrm{p}<.001, \mathrm{MS}_{\mathrm{e}}=2.07\right]$ and Retention Interval $\left[\mathrm{F}(2,48)=54.20, \mathrm{p}<.001, \mathrm{MS}_{\mathrm{e}}=2.61\right]$, and a significant interaction between the two $[F(10,240)=$ $\left.2.93, \mathrm{p}<.01, \mathrm{MS}_{\mathrm{e}}=2.36\right]$. Similarly, the obtained function for the retention condition of Experiment II was also concave downward, as shown in Figure 2. These data suggest that the downturn may not be due to a retrieval time problem.

A trend analysis (Keppel, 1973) was performed on the five- and nine-trial retention interval conditions of Experiment I and the repetition condition of Experiment II. These analyses revealed a significant quadratic component for the five-trial $[F(1,120)=13.02$, $\mathrm{p}<.001]$ and nine-trial $[\mathrm{F}(1,120)=3.92, \mathrm{p}<.05$, $\left.\mathrm{MS}_{\mathrm{e}}=2.07\right]$ retention intervals of Experiment $\mathrm{I}$ and for the repetition condition of Experiment II $[F(1,120)$ $=3.93, \mathrm{p}<.05, \mathrm{MS}_{\mathrm{e}}=3.19$ ].

The response time data for the single-presentation conditions of Experiment II revealed that on correct trials the zero retention interval condition was responded to the fastest $[F(9,216)=13.05, p<.001$, $\left.\mathrm{MS}_{\mathrm{e}}=.41\right]$. Further, no differences were found between the remaining eight single-presentation conditions $(F<1)$. The mean response time was $1.75 \mathrm{sec}$ for the zero condition and ranged from 2.95 to $3.31 \mathrm{sec}$ for the remaining conditions. The response time data for the repetition conditions revealed that the Lag 1 condition resulted in a faster response time (mean $=2.15 \mathrm{sec}$ ) than the other five lag conditions (range of 2.51 . $2.76 \mathrm{sec})\left[\mathrm{F}(5,120)=4.01, \mathrm{p}<.01, \mathrm{MS}_{\mathrm{e}}=.18\right]$.

\section{Evaluation of Independence Hypotheses}

A power function was fit to the data obtained from the single-presentation conditions in each study. They are shown in Figure 1. The values from these functions were used to generate the expected values based on the independence hypothesis. In all cases, functions generated from the independence hypothesis are monotonically decreasing and, since they are obviously different from the observed data, they are not shown in Figure 2. Using a method suggested by Lewis (1960), a goodness-of-fit test for related samples was performed comparing the expected and observed functions. In all three cases, the observed function was significantly different from the function expected by the independence hypothesis $\left[\mathrm{F}(6,240)=3.51, \mathrm{p}<.05, \mathrm{MS}_{\mathrm{e}}=\right.$ 2.36 for the five-trial retention interval of Experiment $\mathrm{I}$; $\mathrm{F}(6,240)=2.98, \mathrm{p}<.01, \mathrm{MS}_{\mathrm{e}}=2.36$ for the nine-trial retention interval of Experiment $I$; and $F(6,120)=2.72$, $\mathrm{p}<.05, \mathrm{MS}_{\mathrm{e}}=3.19$ for the repetition condition of Experiment II]. As noted earlier, the results of the trend analyses indicated a significant quadratic component. As one would expect, no differences were found when the best-fitting quadratic functions were compared to the observed data $(F s<1)$. For the five- and nine-trial retention interval conditions of Experiment I and the repetition conditions of Experiment II, the observed proportion appears to be somewhat below that expected by an independence hypothesis for lags of one to three trials. However, for lags of five to nine trials the ob-

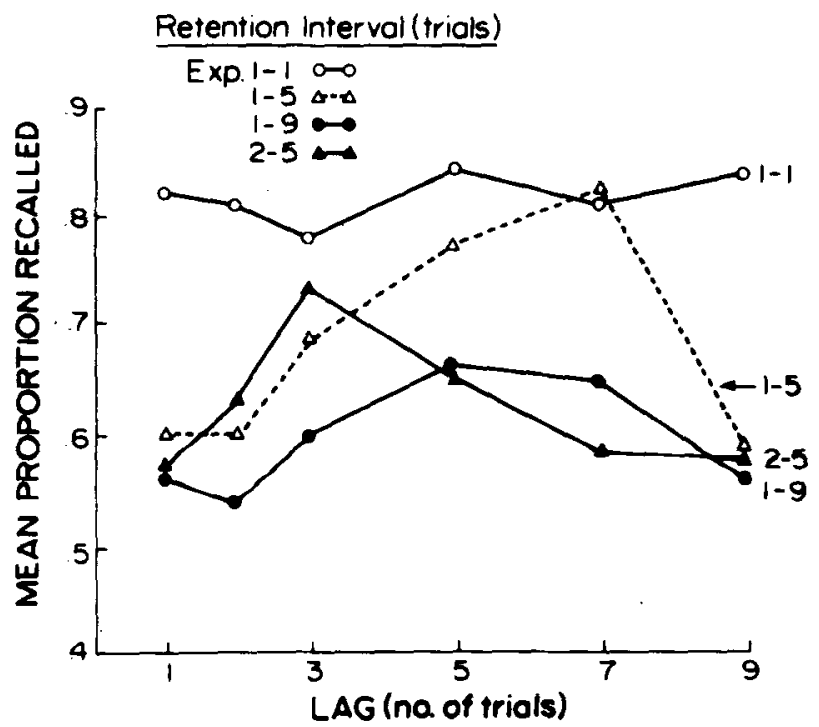

Figure 2. Mean proportion recalled as a function of lag and retention interval. 
served proportion is first greater than, and then either equal to or less than, that expected by the independence hypothesis.

\section{DISCUSSION}

Let us summarize our major findings at this point. We confirmed the previous reports of an interaction between lag and retention interval (Peterson et al., 1962; Robbins \& Bray, 1974a,b) and of the limit to the spacing effect when a relatively long retention interval is used (Bellezza et al., 1975; Peterson et al., 1963; Robbins \& Bray, 1974b; Young, 1971). For a moderately long retention interval, the observed proportion recalled as a function of lag is concave downward. Further, as the lag between repetitions increases, the observed proportion recalled is first less than that expected by an independence hypothesis, eventually exceeds it, and finally falls to the expected level again.

All of the previous studies cited above that have found the concave downward function relating recall level and lag have used a fixed test trial duration. It may have been argued that the downturn represents a retrieval time problem and, if subjects were given an unlimited time to respond, the lag function would not decline. In Experiment II, test trials were subject paced. Despite this, the lag function did reveal a concave downward curve. In fact, the response time data is very similar to that of Bellezza et al. (1975), in that the shortest lag yielded the fastest time, with little difference between the other lag values. Thus, we can reject a retrieval time problem as a possible cause of the downturn in the lag function.

The finding that as the lag increases, the observed recall level is first less than, and then approaches, a level that would be expected if the two presentations of a word pair were stored independently seems to support an encoding variability notion. However, since the independence level should be the maximum value for Melton's (1970) view, it is unclear how this view would predict recall to exceed the independence level and the concave downward function.

There are theories that do predict such a function. For example, both Young (1971) and Sperber, Greenfield, and House (1973) assume that during interpolated trials the "memorial code" may be lost and that this is optimal at moderate lags. Further, the loss of a code leaves the item in a state from which there is a much higher probability of being transferred to a longterm state in contrast to transfer from a short-term state. Atkinson and Shiffrin (1968), on the other hand, assume that information loss from a long-term state occurs as a function of the time that has elapsed since the code was transferred from a short-term to a long. term state. All three of these theories generate concave downward lag functions for relatively long retention intervals. How, then, do they expect more information to be available at moderate lags than would be expected from an independence hypothesis? One answer is that loss of a code ultimately leads to a "better" code in long-term memory (Sperber et al., 1973; Young, 1971). For Atkinson and Shiffrin (1968) this occurs because, although increased time in the short-term buffer provides for more opportunities to transfer information to a long-term store, loss of information from longterm memory occurs if the material has been out of short-term memory for a relatively long period of time. The present data do no discriminate among these views. In any event, these data add additional information that must be accounted for by an adequate theory of the spacing effect and, more generally, repetition effects.

\section{REFERENCE NOTES}

1. Robbins, D. Some implications of memorial phenomena for discrimination learning: Dual-storage dual-retrieval theory of associations. Emory University, Department of Psychology. Technical Report 73-1, 1973.

\section{REFERENCES}

Atkinson, R, C., \& Shiffrin, R. M, Human memory: A proposed system and its control processes. In $K$. W. Spence \& J. T. Spence (Eds.), The psychology of leaming and motivation (Vol. 2). New York: Academic Press, 1968, 99-195.

Bellezza, F. S., Winkler, H. B., \& ANdrasik, F., JR. Encoding process and the spacing effect. Memory \& Cognition, 1975, 3, 451-457.

Buork, R. A. Repetition and rehearsal mechanisms in models for short-term memory. In D. A. Norman (Ed.). Models of human memory. New York: Academic Press, 1970. Pp. 307-332.

Glanzer. M. Distance between related words in free recall: Trace of the STS. Journal of Verbal Learning and Verbal Behavior, 1969, 8, 105-111.

Glanzer, M., \& Duarte, A. Repetition between and with languages in free recall. Joumal of Verbal Learning and Verbal Behavior, 1971, 10, 625-630.

Greeno, J. G. Conservation of information-processing capacity in paired-associate memorizing. Joumal of Verbal Learning and Verbal Behavior, 1970, 9, 581-586.

Hintzman, D. L. Theoretical implications of the spacing effects. In R. L. Solso (Ed.), Theories of cognitive psychology: The Loyola symposium. Washington. D.C: Winston, 1974.

KePPEL, G. Design and analysis: A researcher's handbook. Englewood Cliffs, N.J: Prentice-Hall, 1973.

LEwIS, D. Quantitative methods in psychology. New York: McGraw-Hill, 1960.

Madigan, S. A. Intraserial repetition and coding processes in free recall. Journal of Verbal Learning and Verbal Behavior. $1969,8,828-835$.

Melton, A. W. The situation with respect to the spacing of repetitions and memory. Journal of Verbal Learning and Verbal Behavior. 1970, 9, 596-606.

PaIvio, A. Spacing of repetitions in the incidental and intentional free recall of pictures and words. Journal of Verbal Learning and Verbal Behavior, 1974, 13, 497-511.

Peterson, L. R. Short-term verbal memory and learning. Psychological Review, 1966, 73, 193-207.

Peterson, L. R., Hillner, K., \& Saltzman, D. Time between pairings and short-term refention. Journal of 
Experimental Psichology, 1962. 64. 550-551.

Peterson, L. R.. \& Peterson. M. J. Short-term retention of individual verbal items. Joumal of Experimental Psychology, 1959, 58. 193-198.

Peterson, L. R., Wampler, R., Kirkpatrick. M., \& Saltzman, D. Effect of spacing presentations on retention of a paired-associate over short intervals. Joumal of Experimental Psychology, 1963, 66. 206-209.

Robrins. D., \& Bray, J. F. The spacing effect and the A-B A.C paradigm: Evidence for retroactive facilitation. Journal of Experimental Psychology. 1974, 103. 420-425. (a)

RobBINs. D.. \& BRAY, J. F. Repetition effects and retroactive facilitation: Immediate and delayed recall performance. Bulletin of the Psychonomic Society, 1974, 3, 342-349. (b)

Sperber, R. D.. Greenfield, D. B., \& House, B. J.
A nonmonotonic effect of distribution of trials in retardate learning and memory. Joumal of Experimental Psychology. 1973. 99. 186.198.

THORNDIKE, E. L.. \& LORGE. I. The teacher's word book of 30.000 words. New York: Teachers College Press. Columbia University, 1944

Young. J. L. Reinforcement-test intervals in paired-associate learning. Joumal of Mathematical Psychology, 1971. 8 . 58-81.

(Received for publication September 11. 1975: revision accepted January 21, 1976.) 